\title{
Longitudinal dispersion coefficient in compound open channel with rigid vegetation on flood plain
}

\author{
Alireza Keshavarzi ${ }^{1,2}$, Maryam Farzadkhoo ${ }^{2}$, Hossein Hamidifar ${ }^{2}$ \\ ${ }^{1}$ Centre for Inf. Eng., School of Comp, Eng. and Math, Western Sydney University, Penrith, Australia \\ ${ }^{2}$ Water Engineering Department, Shiraz University, Shiraz, Iran
}

\begin{abstract}
The longitudinal dispersion is a key element in determining the distribution of pollutant in rivers and waterways with vegetation on the flood plains. The focus of this study is on the effect of rigid vegetation characteristic (arrangement patterns) and different relative flow depths on longitudinal dispersion coefficient in a rectangular laboratory flume with compound cross section. Cylindrical piles with $5 \mathrm{~mm}$ diameter were attached on the flood plain to model rigid vegetation. Potassium permanganate $(\mathrm{KMnO} 4)$ has been used as a conservative tracer. Digital image processing technique with imaging from tracer cloud in MATLAB was used for measuring of tracer concentration in three sections downstream of the injection. The results indicated that vegetation could be highly influential on longitudinal dispersion. As the tracer cloud moves downstream, the maximum tracer concentration decreases up to $66 \%$ for a specific relative depth $(\mathrm{Dr}=0.56)$. The longitudinal dispersion values in tandem and patch arrangement were found to be $39.2 \%$ and $86.6 \%$ greater than those in non-vegetated tests. Also, for all vegetation conditions tested in this study, the longitudinal dispersion coefficient increases with increasing the relative depth. Moreover, for a specific relative depth the longitudinal dispersion coefficient increases in patchy arrangement when compared to tandem arrangement.
\end{abstract}

\section{Introduction}

The dispersion of pollutants in flow are usually in three dimensions (vertical, lateral, and longitudinal) for rivers and natural streams. Once full cross-sectional mixing has occurred, the longitudinal dispersion becomes the dominant process. Physically the dispersion arises due to turbulent diffusion and gradient in flow velocity distribution [1]. Flow discharge, flow depth, transverse and vertical profile of velocity, Froude number, secondary flow, channel width, bed slope, and bed roughness are the most crucial parameters which affect the longitudinal dispersion coefficient in rivers [2-6].

1 Corresponding author; $\underline{\text { A.Keshavarzy@westernsydney.edu.au }}$ 
Field experiment of pollutant transport in rivers are much costly and a time consuming process. Although field method can predict the longitudinal dispersion coefficient correctly and accurately, with changing the geometry of rivers and the hydraulic conditions even in the tested river, using the results of field experiments needs more caution. Also, the empirical equations may predict the longitudinal dispersion coefficient with significant error for different boundary conditions. Therefore, The accurate pollutant behaviour must be experimentally specified by reconstructing the different conditions exist in the environment.

One-dimensional pollutant transport after the initial time for full mixing in vertical and lateral direction can be written as follows [7]:

$$
\frac{\partial c}{\partial t}+\frac{\partial(u c)}{\partial x}=\frac{\partial}{\partial x}\left(k \frac{\partial c}{\partial x}\right)
$$

Where; $c$ is the concentration of pollutant, $u$ is the time averaged velocity in longitudinal direction, $t$ is time after the start of injection, and $k$ is longitudinal dispersion coefficient. Once the concentration-time curve were measued, the change of moment method proposed by [8] was adopted to estimate the dispersion coeffcinet, which results to be given by the expression

$$
k=\frac{u^{2} \cdot\left(\sigma_{2}^{2}-\sigma_{1}^{2}\right)}{2 \cdot\left(\overline{t_{2}}-\overline{t_{1}}\right)}
$$

Where; $\sigma^{2}$ is the variance of the concentration curves, $\bar{t}$ is the mean passage time of the tracer cloud, and the subscripts refer to the measure sections.

One of the important zones of researches is concerning the influence of vegetation on the dispersion of pollutant that has been extensively overlooked [9-15]. A study by [13] showed that the longitudinal dispersion coefficient in vegetated rivers can be increased by $70-100 \%$ compared to non-vegetated case. In the presence of vegetation, velocity shear $\left(\mathrm{U}_{*}=\sqrt{g R S_{f}}\right)$ can be the vital source of longitudinal dispersion, $g$ is gravitational acceleration, $R$ is the hydraulic radius, and $S_{f}$ is the water surface slope. To highlight the effect of vegetation on flow structure [16] revealed that in the presence of vegetation, recirculation zones behind each stem traps and delays a fraction of mass, causing enhancement of the longitudinal dispersion.

Generally, natural rivers are composed of two areas; a main channel placed in a lower level and flood plain(s) with higher bed elevation placed in one or both sides of the main channel. In order to demonstrate the depth of flow in compound channels a dimensionless parameter is defined as:

$$
\mathrm{D}_{\mathrm{r}}=(\mathrm{H}-\mathrm{h}) / \mathrm{H}
$$

Where; $D_{r}$ is the relative depth, $H$ is the flow depth in main channel, and $\mathrm{h}$ is the flood plain height. Although, many laboratory experiments were conducted to investigate the effect of vegetation on pollutant transport in simple channels, there is not enough information about the effect of different arrangement of vegetation on longitudinal dispersion in compound channels. Therefore, the main purpose of the present study is to show how relative depth and the presence of vegetation and its different arrangements affect the longitudinal dispersion coefficient in a laboratory channel with compound cross section.

\section{Materials and methods}

The experiments were carried out in a recirculating laboratory flume with $8 \mathrm{~m}$ long, $0.6 \mathrm{~m}$ high, $0.1 \mathrm{~m}$ wide main channel, and $0.15 \mathrm{~m}$ wide flood plain formed an asymmetric compound channel with rectangular cross section. The channel bed slope was 0.001 . The 
flow discharge was measured by a Danfos electromagnetic flow meter located on the outlet pipes of the static tank. The tail gate was adjusted at the downstream end of the channel to prepare uniform flow during experiments. A schematic diagram of the experimental setup and the measuring system is shown in Figure 1.

The cylindrical metal stems, $5 \mathrm{~mm}$ diameter, were placed over floodplain in tandem and patch arrangements. The height of the stems was set to $0.17 \mathrm{~m}$ as emergent vegetation in all flow depths. The vegetation array was $8 \mathrm{~m}$ long over flood plain. The longitudinal distance between stems was $0.04 \mathrm{~m}$. The first row was set at $0.03 \mathrm{~m}$ from the edge of the flood plain and main channel. The distance between two rows was $0.03 \mathrm{~m}$ in lateral direction. The vegetation density (the area of vegetation per unit area of water) was $0.65 \%$ and $0.36 \%$ in tandem and patchy arrangements, respectively. The top view of laboratory flume in patchy arrangement is depicted in Figure 2. In Figure 2, the $b_{m}$ and $b_{f}$ are the main channel and flood plain widths, respectively.

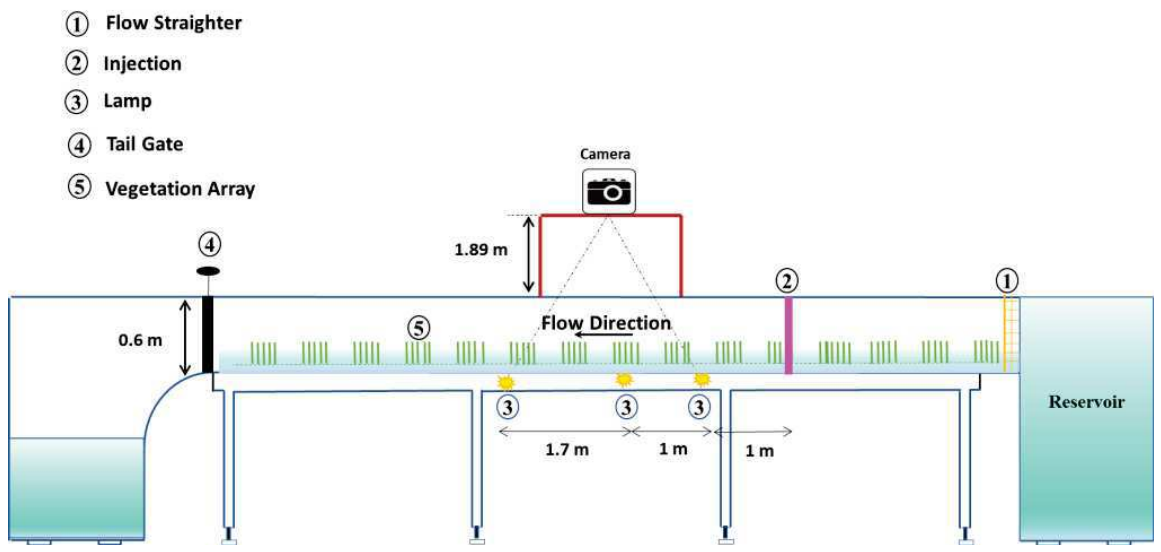

Fig. 1. Plan view of experimental flume (Not in scale)

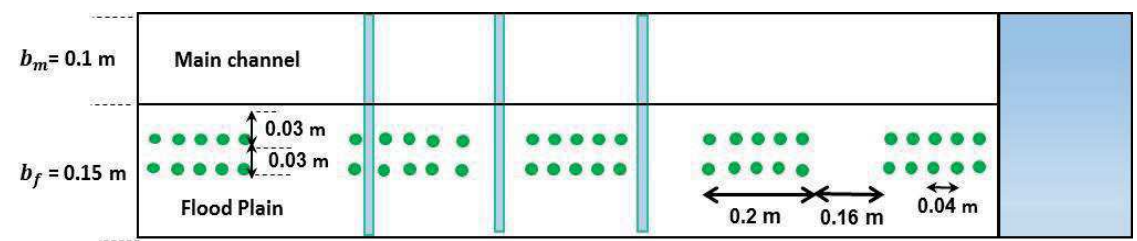

Fig. 2. The schematic top view of laboratory flume in patchy arrangement of vegetation (Not in scale)

In this study, the channel size and the flow relative flow depth is selected such that the possibility of the momentum exchange area has been provided between main channel and flood plain for all three relative flow depths [17].

A high concentration solution $(10 \mathrm{~g} / \mathrm{l})$ of potassium permanganate $(\mathrm{KMnO} 4)$ was used as conservative tracer. The $(\mathrm{KMnO} 4)$ was injected instantaneously as a full-transverse line (Figure 1). After injection, the vertical dispersion occurs quickly in a short distance. Then the longitudinal dispersion would be an imperative factor in mixing. Consequently, it is essential to choose the distance of the first measuring station downstream of the injection apparatus where the injected dye disperses fully in vertical direction. According the initial tests and visual observation the first measurement station was placed $1 \mathrm{~m}$ downstream of the injection point. Three lamps covered with grey cellophanes were placed at the bottom of the channel to illuminate the tracer cloud. A digital camera (HD video recording, 30 frames 
per second) were installed to capture videos continuously before and after the passage of the tracer cloud from each measurement station. In image processing technique the pixel intensity is related to the concentration of dye material with Beer Lambert Law which expressed by [15]. Finally, the longitudinal dispersion coefficient was measured using digital image processing technique in MATLAB Software. The main characteristics of the experiments are summarized in Table 1.

Table 1. Summary of the experimental series and main hydraulic characteristics

\begin{tabular}{cccccc}
\hline $\begin{array}{c}\text { Exp. } \\
\text { name }\end{array}$ & $\boldsymbol{D}_{\boldsymbol{r}}$ & $\begin{array}{c}\mathbf{H} \\
(\mathbf{m})\end{array}$ & $\begin{array}{c}\text { H-h } \\
\mathbf{( m )}\end{array}$ & $\begin{array}{c}\text { Vegetation } \\
\text { density }\end{array}$ & Vegetation condition \\
\hline N1 & 0.34 & 0.076 & 0.026 & - & Non-Vegetated \\
N2 & 0.46 & 0.093 & 0.043 & - & Non-Vegetated \\
N3 & 0.56 & 0.114 & 0.064 & - & Non-Vegetated \\
T1 & 0.34 & 0.076 & 0.026 & $0.65 \%$ & Tandem \\
T2 & 0.46 & 0.093 & 0.043 & $0.65 \%$ & Tandem \\
T3 & 0.56 & 0.114 & 0.064 & $0.65 \%$ & Tandem \\
P1 & 0.34 & 0.076 & 0.026 & $0.36 \%$ & Patch \\
P2 & 0.46 & 0.093 & 0.043 & $0.36 \%$ & Patch \\
P3 & 0.56 & 0.114 & 0.064 & $0.36 \%$ & Patch \\
\hline
\end{tabular}

\section{Results and discussions}

To find the longitudinal dispersion coefficient, the time-concentration curve should be attained for three stations downstream of the injection point. Figure 3 shows some examples of the variation of concentration profiles for different experimental tests; P1, and P2 at measuring stations in flood plain. The diagrams indicate the effect of different relative flow depths on the variation of concentration profiles for vegetated flood plain with patchy arrangement. It can be seen that as the injected red dye moves downstream, the peak concentration reduces up to $66 \%$ for a specific relative depth $(D r=0.56)$. The results are in agreement with the results of previous studies $[15,18]$. Also, by moving the red tracer downstream of the injection, the concentration distribution is extended to the downstream. By increasing the relative flow depth, the maximum concentration decreases from three stations downstream of the injection site. Also, moving the tracer cloud lasts longer in lower relative flow depth.

Longitudinal dispersion coefficient was obtained from the change in variance of tracer profiles using standard moment method (Equation 2). Table 2 indicates the magnitude of the longitudinal dispersion coefficient in non-vegetated and vegetated (Tandem and patch arrangement) flood plain in different relative depths. It can be seen that for all cases of vegetated and non-vegetated the longitudinal dispersion coefficient increases with relative depth. For a given relative depth, longitudinal dispersion coefficient increases for tests with vegetated flood plain (Tandem and patch arrangement) compared to non-vegetated conditions. In other words, comparison with non-vegetated flood plain the longitudinal dispersion coefficient increases up to the $39.2 \%$ and $86.6 \%$ in tandem and patch arrangement, respectively. This finding is in agreement with the results of [16] who show that the vegetation causes the longitudinal dispersion increases significantly. In a specific relative depth the longitudinal dispersion coefficient in patch arrangement increases with regard to tandem arrangement. One may expect that the presence of vegetation in tandem arrangement near the edge of flood plain and main channel act as a wall which reduces the momentum exchange between flood plain and main channel. However, The spaces between vegetation in patchy arrangement causes the momentum exchange increases near the edge of flood plain and main channel which increases the longitudinal dispersion. 

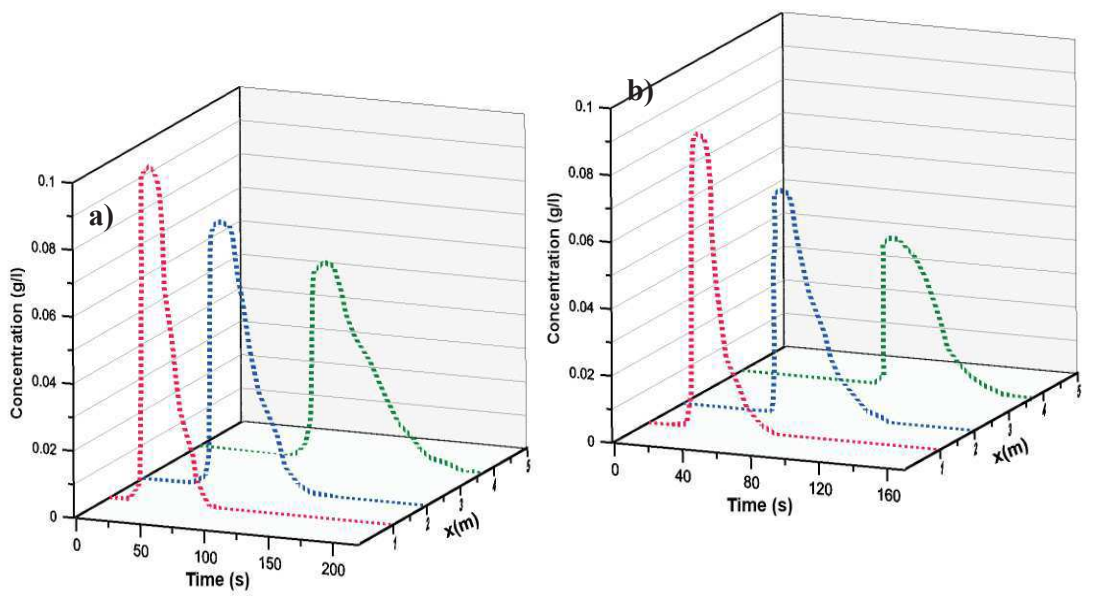

Fig. 3. The variation of concentration-time profiles over vegetated flood plain with patchy c)

Table 2. Summary of the experimental tests and main hydraulic characteristics

\begin{tabular}{cccc}
$\boldsymbol{D}_{\boldsymbol{r}}$ & Non-vegetated & $\begin{array}{c}\text { Tandem } \\
\text { arrangement }\end{array}$ & $\begin{array}{c}\text { Patch } \\
\text { arrangement }\end{array}$ \\
\cline { 2 - 4 } & $\mathrm{K}(\mathrm{m} 2 / \mathrm{s})$ & $\mathrm{K}(\mathrm{m} 2 / \mathrm{s})$ & $\mathrm{K}(\mathrm{m} 2 / \mathrm{s})$ \\
\hline 0.34 & 0.0015 & 0.0016 & 0.0028 \\
0.46 & 0.0024 & 0.0029 & 0.0030 \\
0.56 & 0.0028 & 0.0039 & 0.0041 \\
\hline
\end{tabular}

Figure 4 compares the new longitudinal dispersion data of patchy arrangement of vegetation in the present study (P1, P2, and P3) with some longitudinal dispersion coefficient data collected by $[13,15,19]$. It can be seen that the longitudinal dispersion coefficient increases with $U_{* H}$ for all the experimental datas except those measured by [19] who used flexible natural vegetation in a laboratory flume with simple cross section. [13, 15] both estimated the longitudinal dispersion coefficient in tandem arrangement of vegetation.

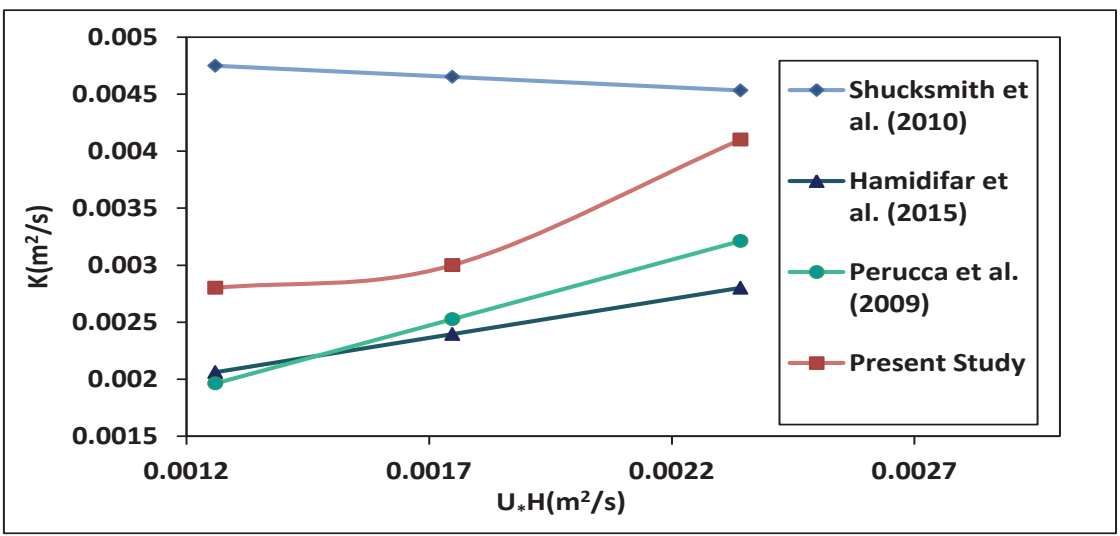

Fig. 4. Comparison of the longitudinal dispersion coefficient against different $U_{*} H$ 
From Figure 4 it is seen that the longitudinal dispersion coefficient of the present study for all relative depths are more than the data proposed by $[13,15]$ which can be a proof for the results of present study that shows in a specific relative depth the longitudinal dispersion coefficient in patchy arrangement of vegetation increases when compared to tandem arrangement.

\section{Conclusion}

The influence of tandem and patchy arrangements of vegetation on longitudinal dispersion coefficient has studied in a compound open channel. Image processing technique has been used to estimate the longitudinal dispersion coefficient in different relative flow depths and different arrangements of vegetation over flood plain. As the injected tracer cloud moves along the flume, the peak of the concentration curve reduces and extends the concentration distribution to the downstream of channel. It was found that moving of tracer cloud lasts longer in lower relative flow depths. For all vegetation conditions used in this study, the longitudinal dispersion coefficient increases with increasing the relative flow depth. For a specific relative flow depth, the longitudinal dispersion coefficient increases for tests with vegetated flood plain when compared to the non-vegetated conditions. It is observed that in comparison with non-vegetated case, the longitudinal dispersion coefficient increases up to $39.2 \%$ and $86.6 \%$ in tandem and patchy arrangements, respectively. Moreover, in a specific relative flow depth, the longitudinal dispersion coefficient in patchy arrangement increases when compared to the tandem arrangement. Further studies are required by changing different types of vegetation and also different plant densities to extend the findings of the present study.

\section{References}

1. K.O. Baek, I.W. Seo, K.W. Lee, J. Korean Soc. Civ Eng. 26, 4B, 371-378 (2006)

2. I.W. Seo, T.S. Cheong, J. Hydraul. Eng. 124, 1, 25-32 (1998)

3. I. Guymer, J. Hydraul. Eng. 124, 1, 33-40 (1998)

4. J.B. Boxall, I. Guymer, Water Res. 41, 2, 341-354 (2007)

5. A. Etemad-Shahidi, M. Taghipour, J. Hydraul. Eng. 138, 6, 542-554 (2012)

6. T. Disley, B. Gharabaghi, A.A. Mahboubi, E.A. McBean, Hydrol. Processes. 29, 2 , 161-172 (2015)

7. J.C. Rutherford, River Mixing Wiley (Chichester UK Google Scholar, 1994)

8. C.F. Nordin, B.M. Troutman, Water Resour. Res. 16, 1, 123-128 (1980)

9. R.M. Li, H.W. Shen, J. Hydraul. Div. 99 (1973).

10. B.L. White, H.M. Nepf, J. Fluid Mech. 487, 43-79 (2003)

11. T. Serra, H.J. Fernando, R.V. Rodriiguez, Water Res. 38, 1, 139-147 (2004)

12. A.F. Lightbody, H.M. Nepf, Limnol. Oceanogr. 51, 1, 218-228 (2006)

13. E. Perucca, C. Camporeale, L. Ridolfi, Adv. Water Resour. 32, 1, 78-87 (2009)

14. H. Tang, S. Lu, Y. Zhou, X. Xu, Y. Xiao, In Proceedings of the Institution of Civil Engineers-Municipal Engineer, 161, 1, 11-16 (2008)

15. H. Hamidifar, M.H. Omid, A.R. Keshavarzi, Ecol. Eng. 84, 398-407 (2015)

16. H.M. Nepf, C.G. Mugnier, R.A. Zavistoski, Estuar. Coast. Shelf Sci. 44, 6, 675-684 (1997)

17. C. Hu, Z. Ji, Q. Guo, J. Hydraul. Res. 48, 1, 23-32 (2010)

18. K.O. Baek, I.W. Seo, Adv. Water Resour. 33, 12,1551-1559 (2010)

19. J.D. Shucksmith, J.B. Boxall, I. Guymer, Water Resour. Res. 46, 4 (2010) 